\title{
Prevalence of Obesity in a Saudi Obstetric Population
}

\author{
Abdel-Hady El-Gilany ${ }^{a}$ Adel El-Wehady \\ ${ }^{a}$ Community Medicine Department, College of Medicine, Mansoura University, Egypt \\ ${ }^{\mathrm{b}} \mathrm{Al}-\mathrm{Hassa}$ Directorate of Health, Saudi Arabia
}

\section{Key Words}

Body mass index - BMI - Obesity - Overweight . Obstetric population - Saudi Arabia

\section{Summary}

Objective: To estimate the prevalence of obesity and its determinants during the first month of gestation in Saudi women. Methods: Retrospective chart review of measured BMI in Al-Hassa, the largest province in Saudi Arabia, in 2007. Data were collected from records of 791 (72.6\% of 1,089$)$ pregnant women registered for prenatal care. Results: Height shows a normal Gaussian distribution, whereas weight is skewed positively (skewness of 0.77). The prevalence of underweight, normal weight, overweight, obesity, and extreme obesity (BMI > $40 \mathrm{~kg} / \mathrm{m}^{2}$ ) were $8.5,39.3,23.6,23.9$, and $4.7 \%$, respectively. Logistic regression revealed that the most important significant independent predictors of obesity are parity of 4 and more (odds ratio $(O R)=5.8$ ) and urban residence ( $O R=4.9$ ). Conclusion: Overweight, obesity, and extreme obesity are common (>52\%) among pregnant women in Saudi Arabia. Health education to control body weight before pregnancy is warranted.

\section{Introduction}

The rising rate of obesity is a major public health concern in the West, where $28 \%$ of pregnant women are overweight and $11 \%$ are obese [1]. Research indicates that a woman who is overweight or obese before she becomes pregnant also has a higher risk of complications during her pregnancy and higher prevalence of health problems for her children. This new information is especially troubling in light of the current obes- ity epidemic. The epidemic is especially pronounced in young people, including women of reproductive age [2,3]. Several studies of the prevalence of obesity and overweight in the general population of Saudi Arabia have reported high prevalences for both sexes [4-10]. One study of Saudi non-pregnant women of childbearing age revealed that $31.5 \%$ were overweight and $21.1 \%$ were obese [11].

Despite these alarming figures, to the best of our knowledge no studies have been done on the prevalence of obesity among pregnant women in the Kingdom of Saudi Arabia. As the first phase of an ongoing prospective study to examine the effects of BMI on pregnancy outcomes, this study aims to examine the prevalence and independent predictors of obesity in early pregnancy in Al-Hassa, Saudi Arabia.

\section{Material and Methods}

During 2007, initial antenatal care visits were carried out in Al-Hassa, the largest province in Saudi Arabia's Eastern region (population of 908,366) covering an area of $534,000 \mathrm{~km}^{2}$. The total population of Saudi Arabia is approximately 27.6 million. Maternity care in Al-Hassa is provided through a network of 47 primary health care centers (PHCCs) covering urban, rural, and Hegar (in the Bedouin desert) areas in addition to facilities in the private sector, ARAMCO Petroleum Company and National Guard and Maternity Hospital. Health care services provided by the governmental sector in Saudi Arabia account for over $80 \%$ of total services and are almost free of charge. Health statistics of the region reveal that about $1.5 \%$ of deliveries take place in PHCCs and only less than $0.5 \%$ were home births, mostly in Hegar. The implemented antenatal care was the classic schedule with 13 visits throughout pregnancy. Eligible candidates were all women attending for antenatal care in PHCCs within the first month of pregnancy. Exclusion criteria were pre-pregnancy chronic medical disease (hypertension, diabetes, renal, cardiac, and sickle cell disease) and multiple (non-singleton) gestation. Mothers were counseled and assured that data collected will be dealt with confidentially. They gave verbal consent prior to the interview. The study was approved by the Al-Hassa Directorate of Health.

\begin{tabular}{ll}
\hline KARGER & @ 2009 S. Karger GmbH, Freiburg \\
Fax +497614520714 & Accessible online at: \\
$\begin{array}{l}\text { Information@Karger.de } \\
\text { www.karger.com }\end{array}$ & www.karger.com/ofa \\
&
\end{tabular}

Abdel-Hady El-Gilany, MD

Community Medicine Department, College of Medicine

Mansoura University

Mansoura 35516, Egypt

ahgilany@gmail.com 
Table 1. Prevalence of obesity according to some maternal sociodemographic factors

\begin{tabular}{|c|c|c|c|c|}
\hline & Total & Obesity, n (\%) & Significance test & OR $(95 \% \mathrm{CI})$ \\
\hline \multicolumn{5}{|l|}{ Residence } \\
\hline Hegar & 45 & $6(13.3)$ & \multirow{3}{*}{$\chi^{2}=16.4^{b}$} & $1(\mathrm{r})$ \\
\hline Rural & 323 & $75(23.2)$ & & $1.7(0.8-3.8)$ \\
\hline Urban & 423 & $145(34.3)$ & & $2.6(1.2-5.5)$ \\
\hline \multicolumn{5}{|l|}{ Family income } \\
\hline Unsatisfactory & 264 & $55(20.8)$ & \multirow{2}{*}{$\chi^{2}=11.6^{\mathrm{b}}$} & $1(\mathrm{r})$ \\
\hline Satisfactory & 527 & $171(32.4)$ & & $1.56(1.2-2.0)$ \\
\hline \multicolumn{5}{|l|}{ Age, years } \\
\hline$<20$ & 63 & $11(17.5)$ & \multirow{4}{*}{$\chi^{2}=30.7^{\mathrm{b}}$} & $1(\mathrm{r})$ \\
\hline $20-29$ & 452 & $104(23.0)$ & & $1.3(0.8-2.3)$ \\
\hline $30-39$ & 228 & $88(38.6)$ & & $2.2(1.3-3.9)$ \\
\hline$\geq 40$ & 48 & $23(47.9)$ & & $2.7(1.5-5.1)$ \\
\hline \multicolumn{5}{|l|}{ Parity } \\
\hline Nulliparous & 229 & $30(13.1)$ & \multirow[t]{3}{*}{$\chi^{2}=58.7^{b}$} & $1(\mathrm{r})$ \\
\hline 2 and 3 & 305 & $82(26.9)$ & & $2.3(1.4-3.0)$ \\
\hline 4 and more & 257 & $114(44.4)$ & & $3.4(2.4-4.9)$ \\
\hline \multicolumn{5}{|l|}{ Education } \\
\hline$<$ Secondary & 326 & $100(30.7)$ & \multirow[t]{3}{*}{$\chi^{2}=2.2^{\mathrm{a}}$} & $1(\mathrm{r})$ \\
\hline Secondary & 301 & 77 (25.6) & & $0.8(0.7-1.1)$ \\
\hline$>$ Secondary & 164 & 49 (29.9) & & $0.97(0.7-1.3)$ \\
\hline \multicolumn{5}{|l|}{$\overline{\text { Work }}$} \\
\hline Housewives & 639 & $183(28.6)$ & \multirow{2}{*}{$\chi^{2}=0.01^{\mathrm{a}}$} & $1(\mathrm{r})$ \\
\hline Working & 152 & $43(28.3)$ & & $0.99(0.75-1.3)$ \\
\hline Overall & 791 & $226(28.6)$ & & $(25.5-31.8)$ \\
\hline \multicolumn{5}{|c|}{$\begin{array}{l}\text { OR = Odds ratio; } \mathrm{CI}=\text { confidence interval; } \mathrm{r}=\text { reference group. } \\
{ }^{\mathrm{a}} \mathrm{p}>0.05 . \\
{ }^{\mathrm{b}} \mathrm{p}<0.001 .\end{array}$} \\
\hline
\end{tabular}

During the year 2006, the maternity care registry of the Al-Hassa Directorate of Health registered a total of 8,154 mothers for antenatal care at PHCCs, whereas 1,109 (13.6\%) of these mothers started care during the first month of pregnancy.

A pilot retrospective record-based study was carried out with 150 mothers registered for prenatal care at 15 PHCCs to assess the expected prevalence of obesity among the prenatal population to be used for sample size calculation for the full-scale study. The pilot study revealed that 37 $(24.7 \%)$ mothers were obese $\left(\mathrm{BMI} \geq 30 \mathrm{~kg} / \mathrm{m}^{2}\right)$. At $95 \%$ confidence level and $80 \%$ study power, the sample size required is at least 766 mothers.

Throughout 2007, a total of 1,089 mothers registered for prenatal care during the first month of pregnancy. Gestational age was assessed by selfreported last menstrual period. Of these mothers, 791 (72.6\%) were included while 213 (19.6\%) were not included due to exclusion criteria; the other $85(7.8 \%)$ refused to participate in the study.

The sample members were interviewed at the PHCCs by Arabicspeaking female nurse interviewers who trained on data collection. A pre-designed, tested questionnaire was filled out. Data was collected from the family file and maternity cards kept at the PHCCs as well as from the mother during the interview. The Ministry of Health has developed special guidelines for using the card, explaining its contents and how to use it, as well as defining the various measurements, investigations, and their normal limits. The card is shared by the health centers and the hospital. Continuous emphasis is placed on the completeness of this card [12].

At the first antenatal visit, height (in $\mathrm{cm}$ ) and weight (in $\mathrm{kg}$ ) were recorded using a standard technique. Height was measured with a stadiometer accurate to $0.1 \mathrm{~cm}$, with the mother standing and without wearing shoes. Body weight was measured with a calibrated electronic $\left(\mathrm{Seca}^{\circledast}\right)$ scale accurate to $0.1 \mathrm{~kg}$ while subjects were wearing the lightest possible clothes. The data was used to calculate Quetelet's index or the BMI. BMI values are classified into 5 weight categories according to the WHO: un- derweight: $<18.5 \mathrm{~kg} / \mathrm{m}^{2}$, normal weight: $18.5-24.99 \mathrm{~kg} / \mathrm{m}^{2}$, overweight: $25-$ $29.9 \mathrm{~kg} / \mathrm{m}^{2}$, obese $30-39.9 \mathrm{~kg} / \mathrm{m}^{2}$, and extremely obese $>40 \mathrm{~kg} / \mathrm{m}^{2}$ [13-15].

Statistics: Chi-squared test $\left(\chi^{2}\right)$ was used to test the significance between categorical variables in the full-scale study. $\mathrm{p} \leq 0.05$ was chosen as the level of statistical significance using the SPSS version 11 (SPSS Inc.; Chicago, IL, USA). Significant predictors of obesity in univariate analysis were entered into multivariate stepwise forward Wald logistic regression analysis to find out the independent predictors of obesity. The outcome variable is obesity (BMI $\geq 30 \mathrm{~kg} / \mathrm{m}^{2}$ ) including extremely obese women $\left(\mathrm{BMI} \geq 40 \mathrm{~kg} / \mathrm{m}^{2}\right)$. To quantify the risk of different predictors, the relative risk (odds ratio $(\mathrm{OR})$ ) and $95 \%$ confidence intervals $(\mathrm{CI})$ were computed.

\section{Results}

The full-scale study revealed that the values of the mean, median, and mode of height are very similar (155.6, 156, and 155 , respectively), suggesting normal Gaussian distribution with skewness of 0.1 . However, the mean, median, and mode of weight are $64.3,61.5$, and 57.0 , respectively, with positive skewness of 0.77 .

BMI groups are: underweight $8.5 \%$, normal weight $39.3 \%$, overweight $23.6 \%$, obese $23.9 \%$, and extremely obese $4.7 \%$.

Table 1 reveals that obesity is significantly higher among urban women, those with satisfactory family income (meeting their expenses and being able to save as reported by women), older age groups, and those of higher parity. However, logistic 
Table 2. Logistic regression analysis of the significant independent predictors of obesity $^{\mathrm{a}}$

\begin{tabular}{|c|c|c|}
\hline \multirow[t]{2}{*}{ Predictor } & \multicolumn{2}{|c|}{ Obesity } \\
\hline & $\beta$ & OR $(95 \% \mathrm{CI})$ \\
\hline \multicolumn{3}{|l|}{ Parity } \\
\hline Nulliparous & - & $1(\mathrm{r})$ \\
\hline 2 and 3 & 0.97 & $2.6(1.6-4.2)^{\mathrm{d}}$ \\
\hline 4 and more & 1.76 & $5.8(3.7-9.3)^{\mathrm{d}}$ \\
\hline \multicolumn{3}{|l|}{ Residence } \\
\hline Hegar & - & $1(\mathrm{r})$ \\
\hline Rural & 1.2 & $3.2(1.3-7.96)^{\mathrm{b}}$ \\
\hline Urban & 1.6 & $4.9(2.0-12.1)^{\mathrm{d}}$ \\
\hline \multicolumn{3}{|l|}{ Family income } \\
\hline Unsatisfactory & - & $1(\mathrm{r})$ \\
\hline Satisfactory & 0.6 & $1.8(1.2-2.6)^{\mathrm{c}}$ \\
\hline \multicolumn{3}{|c|}{$\begin{array}{l}\text { OR }=\text { Odds ratio } \text { CI }=\text { confidence interval; } \\
\mathrm{r}=\text { reference group. } \\
{ }^{\mathrm{a} C} \text { Constant: }-3.7 ; \text { percent correctly predicted: } \\
72.9 ; \text { model } \chi^{2}: 91.9, \mathrm{p}=0.000 . \\
{ }^{\mathrm{b}} \mathrm{p}<0.05 \\
{ }^{\mathrm{c}} \mathrm{p}<0.01 \\
{ }^{\mathrm{d}} \mathrm{p}<0.001\end{array}$} \\
\hline
\end{tabular}

regression revealed that the most important significant independent predictors of obesity are parity of 4 and more $(\mathrm{OR}=$ $5.8)$, urban residence $(\mathrm{OR}=4.9)$, and satisfactory family income $(\mathrm{OR}=1.8)($ table 2$)$.

\section{Discussion}

Obesity is the most common nutritional disorder in developed countries and is becoming significant in developing countries, and more women in the fertile ages become overweight and obese. Obese women have higher risks of complications during pregnancy $[16,17]$.

Our results showing mean height, mean weight, and mean BMI of $155.6 \mathrm{~cm}, 64.3 \mathrm{~kg}$, and $26.5 \mathrm{~kg} / \mathrm{m}^{2}$, respectively, are in general agreement with a recent study of non-pregnant Saudi Women of childbearing age [11]. However, our prevalence of obesity $(23.9 \%)$ and extreme obesity $(4.7 \%)$ is much greater than the combined rate of obesity and extreme obesity in the non-pregnant population (21.1\%). In 1992, it was reported that Saudi women are on average more obese than their European counterparts [8].

Logistic regression analysis revealed that the independent predictors of obesity in the studied population are parity, place of residence, and family income. Compared to nulliparous women, the risk of obesity rises 5.8-fold among mothers with parity of 4 or more and 2.6-fold with 2 or 3 pregnancies. This agrees with other studies [18-20]. The increased parity of women in higher BMI categories may be related to the tendency to gain weight with each pregnancy [19].

Urban mothers are about 5 times and rural mothers are about 3 times more likely to be obese than nomadic Bedouins.
This is a reflection of the sedentary life of urban residents. The rapid urbanization of rural areas will mask the differences between urban and rural localities. The Hegar population is poor, living primitively with great reliance on natural food and high energy expenditure, searching for grass to feed their animals.

Women with satisfactory family income are about 2 times more likely to be obese than those with unsatisfactory income. Again, this is a reflection of food consumption and sedentary lifestyle. It was reported that obesity is associated with high social class in some other populations, too $[18,20]$. Obesity is the result of complex interaction between multiple factors. High social class is associated with excess energy intake and low physical activity; both of these are characteristics of the Saudi society. Obesity and overweight are frequent in the Saudi obstetric population and may be regarded as an epidemic in the Saudi population in general.

Health education to control body weight before pregnancy is warranted. Birth control measures to limit parity could contribute, indirectly, to a decrease of obesity among Saudi women.

A nationwide community-based prospective study may provide in-depth knowledge about the prevalence and the wider range of predictors of different categories of BMI. It is important to standardize the definition of BMI range categories to facilitate comparison over time and between different countries.

\section{Study Limitations}

The study is clinic-based and included only mothers attending for care at PHCCs in one region of the kingdom. Late attendees, those who received care at other health sectors, and those not receiving care at all were not included. Furthermore, by excluding women with pre-pregnancy diabetes, hypertension, and other chronic diseases known to be associated with higher BMI and the metabolic syndrome, we might have underestimated the overall prevalence of obesity.

Weight and height were measured at the antenatal booking visit during the first month of pregnancy utilizing BMI cutoff points derived from non-pregnant population in the absence of pre-pregnancy measures, rather than relying on self-reported pre-conception weight. However, it was reported that gestational BMI had a similar predictive capacity as pre-pregnancy BMI [21].

The levels of physical activity and food intake are independent predictors of obesity but were not studied due to lack of validated measurement tools suitable for pregnant women in the Saudi culture.

\section{Disclosure}

The authors declared no conflict of interest. 


\section{References}

1 Royal College of Obstetricians and Gynaecologists: The growing trends in maternal obesity. Press Release, October 5, 2006. www.rcog.org.uk/news/growing-trends-maternal-obesity.

2 Minneapolis Department of Health and Family Sup port: Risks of being overweight for women of reproductive age. Research Brief. January 2008. www. ci.minneapolis.mn.us/dhfs/reproductiveweight.pdf.

3 Guelinckx I, Devlieger R, Beckers K, Vansant G: Maternal obesity: pregnancy complications, gestational weight gain and nutrition. Obes Rev 2008;9: 140-150.

4 Al-Nuaim AR: Population-based epidemiological study of the prevalence of overweight and obesity in Saudi Arabia, regional variation. Ann Saudi Med 1997;17:195-199.

5 El-Hazmi MAF, Warsy AS: Prevalence of obesity in a Saudi population. Ann Saudi Med 1997;17:302-306.

6 Al-Nuaim AR, Al-Rubeaan KA, Al-Mazrou Y, AlAttas O, Al-Daghari N, Khoja T: High prevalence of overweight and obesity in Saudi Arabia. Int J Obes Relat Metab Disord 1996;20:547-552.

7 Rasheed P, Abou-Hozaifa BM, Khan A: Obesity among young Saudi female adults: a prevalence study on medical and nursing students. Public Health 1994;108:289-291.
El-Rehaimi AAR, Björntorp P: Obesity and fat distribution in women from Saudi Arabia. Int J Obes Relat Metab Disord 1992;16:1017-1019.

9 Al-Shammari SA, Khoja TA, Kremli M, Al-Balla SR: Low back pain and obesity in primary health care, Riyadh, Saudi Arabia. Saudi Med J 1994;15: 223-226.

10 Khashoggi RH, Madani KA, Khaznawy HI, Ali MA: Socioeconomic factors affecting the prevalence of obesity among female patients attending primary health care centers in Jeddah, Saudi Arabia. Ecol Food Nutr 1994;31:277-283.

11 Al-Malki JS, Al-Jaser MH, Warsy AS: Overweight and obesity in Saudi females of childbearing age. Int J Obesity 2008;27:134-139.

12 Ministry of Health, Saudi Arabia: Quality Assurance in Primary Health Care Manual, ed 1. WHOEMR/PHC/81-A/G/93. Riyadh, El-Hilal Press, 1994, pp 241-315.

13 WHO: Physical status: the use and interpretation of anthropometry. Report of a WHO Expert Committee. WHO Technical Report Series 854. Geneva, World Health Organization, 1995.

14 WHO: Obesity: prevention and managing the global epidemic. Report of a WHO Consultation. WHO Technical Report Series 894. Geneva, World Health Organization, 2000.
5 WHO Expert Consultation: Appropriate body-mass index for Asian populations and its implications for policy and intervention strategies. Lancet 2004;363: 157-163.

16 Young VR: Good nutrition for all: challenge for the nutritional sciences in the new millennium. Nutr Today 2001;36:6-16.

17 Linné Y: Effects of obesity on women's reproduction and complications during pregnancy. Obes Rev 2004 5:137-143.

18 Callaway LK, Prins JB, Chang AM, McIntyre HD The prevalence and impact of overweight and obesity in an Australian obstetric population. Med J Aust 2006;184:56-59.

19 Koch E, Bogado M, Araya F, Romero T, Díaz C, Manriquez L, Paredes M, Román C, Taylor A, Kirschbaum A: Impact of parity on anthropometric measures of obesity controlling by multiple confounders: a cross-sectional study in Chilean women. J Epidemiol Community Health 2008;62:461-470.

20 Obi SN, Obute EA: Pregnancy outcome in the obese Nigerian. Trop J Obstet Gynaecol 2004;21:32-35.

21 Wendland EMDR, Duncan BB, Mengue SS, Nucci LB, Schmidt MI: Waist circumference in the prediction of obesity-related adverse pregnancy outcomes. Cat Saude Publica 2007;23:391-398. 